\title{
Toxoplasmosis and abortion: pro- and anti- inflammatory cytokines gene expression of the host immune cells
}

\author{
Mona Said El-Sherbini', Amany A. Abd El-Aal ${ }^{1,2}$, Walid Sayed El-Sherbiny ${ }^{3}$, Samar Sayed Attia ${ }^{1,2^{*}}$ (D, \\ Inas Z. Abdel Aziz ${ }^{1}$, Ghada M. Nasr ${ }^{4}$, Mohamed Sayed Salama ${ }^{5}$ and Mohamed S. Badr ${ }^{6}$
}

\begin{abstract}
Background: Toxoplasmosis during pregnancy is known for inducing variable serious outcomes. In many previous studies, pregnancy was evaluated as a single event while in reality; it has different distinct immunological stages depending on gestational time and possible external factors as infectious agents. A state of immunological balance as well as a state of maternal-fetal tolerance should be established; otherwise, atypical unwelcomed outcomes might occur as a result of such infection

Aim: This work aimed to study the gene expression profile of some pro- and anti-inflammatory cytokines in Toxoplasma seropositive cases

Results: All studied cytokines were significantly upregulated in group I, with a remarkable bias towards IFN- , denoting a predominant inflammatory state in group I. In group II; tested cytokines were approximately in a balanced state with a little shift towards anti-inflammatory cytokines (IL-10 and TGF- $\beta$ ). A significant positive correlation was detected between pro-inflammatory together $(p=0.002, r=0.96)$ and between anti-inflammatory cytokines together $(p=0.0008, r=0.99)$ in group II, indicating the harmonized and synchronized expression of both pro- and anti-inflammatory cytokines. In group III, IL-10 was relatively higher with negative correlation with IFN- $\gamma$ ( $p=0.006, r=0.93$ ), indicating the possible role of IL10 in saving some of the pregnancies' outcomes in group III. Conclusion: The present study suggests a potential role of these cytokines in the upcoming prognostic or/and therapeutic concerns of toxoplasmosis among pregnant women.
\end{abstract}

Keywords: Toxoplasma, q-PCR, IFN- $\gamma$, TNF-a, IL10, TGF- $\beta$

\section{Background}

Toxoplasma gondii (T. gondii) is an intracellular parasite with very low host specificity as it probably infects almost all mammals and birds as well. It is endemic worldwide; however, according to the geographic location, 15 to $85 \%$ of the human populations are asymptomatically infected. Infection during pregnancy may lead to dangerous outcomes [1]. Abortions may occur in addition to stillbirths, intrauterine growth retardation, preterm deliveries, or fetal anomalies [2].

\footnotetext{
* Correspondence: ssattia@kasralainy.edu.eg

${ }^{1}$ Department of Medical Parasitology, Faculty of Medicine, Cairo University, Giza, Egypt

${ }^{2}$ Department of Medical Parasitology, Armed Forces College of Medicine (AFCM), Heliopolis, Egypt

Full list of author information is available at the end of the article
}

Although spontaneous abortion due to congenital toxoplasmosis is previously documented, yet it is controversial, to what extent toxoplasmosis is a risk factor and can cause repeated abortion [3, 4]. The previous studies relied on serological data to achieve their objectives, which was not convincing enough as an evidence to understand the relatively complex relation between the parasite and the host immune system [5]. The mechanisms by which Toxoplasma interacts with the host's immune system are still questionable and need further investigations to illuminate such important research area [6].

Host control against $T$. gondii infection requires the induction of strong parasite-specific immune response in the host [7]. Following Toxoplasma infection, neutrophils rapidly migrate to the site of infection, then 
activate dendritic cells (DC) for induction of T-helper 1 (Thl) inflammatory response [8-10]. The infected host generates a strong cytokine-dependent parasite-specific interferon- $\gamma($ IFN $-\gamma)$ response $[11,12]$. Elevated level of IFN- $\gamma$ (Th1 cytokine) inhibits Toxoplasma replication and promotes its transformation from tachyzoite to bradyzoite stage [7, 13]. T-helper 2 (Th2) immune response provokes a significant increase in both $T$. gondii intracellular replication and invasion [14].

Pregnancy was described as a "Th2" or anti-inflammatory status, and any shift in the type of cytokines produced would lead to pregnancy complications $[15,16]$. In previous studies, pregnancy was evaluated as a single event while in reality; it has different distinct immunological stages depending on gestational time and possible external factors as infectious agents $[17,18]$. Therefore, a state of immunological balance as well as a state of maternal-fetal tolerance should be established; otherwise, atypical unwelcomed outcome might occur [19].

With the application of advanced analytical molecular technologies, more exploration of Toxoplasma growth, differentiation, and host-parasite interaction could be achieved [5]. A variety of methods have been used for gene expression quantification, including northern blotting, serial analysis of gene expression (SAGE), DNA microarrays, and quantitative reverse transcription-quantitative polymerase chain reaction (RT-qPCR). The introduction of real-time quantitative PCR techniques is proven useful in various applications, including pathogen detection, gene expression and regulation, and allelic discrimination [20]. The aim of this work was to identify the modulated proinflammatory versus anti-inflammatory cytokine gene expression in the intended study group.

\section{Subjects and methods}

\section{Type of study: a case-control study}

The present study included a total of 61 cases, who were seropositive for toxoplasmosis. Cases were further subdivided according to variable pregnancy outcome into three groups: group I-19 cases complaining of repeated abortions (at least 3 times) with no history of successful pregnancies, group II-28 cases that were multiparous with no history of abortion, and group III-14 cases that had successful pregnancies' outcomes, but also suffered a history of some abortions. To exclude other causes of repeated abortion, further exclusion criteria were set in this study, as women with known thrombophilia, systemic lupus, antiphospholipid syndrome, or any other autoimmune diseases causing recurrent abortions, women with known uterine congenital anomalies, or multi-fetal pregnancies. Immunocompromised women, or those receiving immunosuppressive medications, and any maternal/fetal bacterial or viral infections that cause abortion were also excluded from the study.
Cases included in this study were selected from the outpatient's clinic of Obstetrics and Gynecology Department in Kasr Alainy Hospital, which is governmental, educational, and free-of-charge hospital, during the period from January 2014 to February 2015. All women included were of low educational and socioeconomic levels, without any significant demographic variations. Their age range was between 27 and 36 years old, and all were housewives.

In our study, the gene expression of 4 cytokines was investigated in selected study groups' women, who were seropositive for $T$. gondii, by measuring pro and anti-inflammatory cytokine mRNAs. These cytokines were interferon gamma (IFN- $\gamma$ ), tumor necrosis factor- $\alpha$ (TNF- $\alpha$ ), interleukin 10 (IL-10), and transforming growth factor- $\beta$ (TGF- $\beta$ ). Blood samples were collected from all cases and tested serologically for anti-Toxoplasma IgG/IgM by OnSite Toxo rapid qualitative immune-chromatography test (ICT) (CTK, USA). Anti-Toxoplasma IgG antibodies were detected by ELISA, using Nova Tox IgG (Atlas link, Beijing). The cutoff (optical density (OD)) value was calculated against threshold 0.09 and samples giving higher OD were considered positive. The mononuclear layer was separated from each blood sample by Lymphoprep (Axis-Shield PoC, Norway) density gradient centrifugation, which is a simple and rapid method of purifying peripheral blood mononuclear cells (PBMC).

\section{RNA extraction and reverse transcription PCR (RT-PCR)}

According to the manufacturer's instructions, RNA extraction was done using Commercial kits (The SV Total RNA Isolation System) Promega Corpora on 2800 Woods Hollow Road, Madison, WI 53711-5399 USA. Reverse transcription PCR was performed using HYBAID OmniGene 3 Block Thermal Cycler (Mid-Atlantic Lab.equip., UK). The recommended cDNA synthesis reaction mixture consisted of the following: M-MLV Reverse Transcriptase RNase $\mathrm{H}-200 \mathrm{U} / \mu \mathrm{l}$ (Solis BioDyne) $(1 \mu \mathrm{l}, 4 \mathrm{U} / \mu \mathrm{l})$, $20 \mathrm{mMdNTP}$ mix $(1.25 \mu \mathrm{l}, 500 \mu \mathrm{M}), 100 \mathrm{mM}$ DTT $(2.5 \mu \mathrm{l}$, $5 \mathrm{mM})$, and random hexamer $\mu \mathrm{g}$ of RNA $(2.5 \mu \mathrm{l}, 500 \mathrm{ng})$; RNase inhibitor (Solis BioDyne) $(1 \mu \mathrm{l}, 25 \mathrm{U})$, for $5 \times$ RT reaction buffer $1(10 \mu \mathrm{l}, 1 \times)$, with $\mathrm{MgCl} 2$ and DTT) $0.25 \mathrm{M}$ Tris- $\mathrm{HCl}, 0.5 \mathrm{M} \mathrm{KCl}, 30 \mathrm{mM} \mathrm{MgCl} 2$, and $25 \mathrm{mM}$ DTT; and RNA $(5 \mu \mathrm{l}, 2.5 \mu \mathrm{g})$ and DEPC treated $\mathrm{H}_{2} \mathrm{O}$ to a $50-\mu \mathrm{l}$ final reaction volume.

\section{Microfluidic LabChip RT- real-time PCR}

The procedure was applied on UltraFast LabChip Realtime PCR G2-3 System (NanoBioSys Inc., Korea). Realtime PCR reaction was prepared using SYBR Green I Real-Time PCR Master Mix Kit (NanoBioSys Inc., Korea) (Tables 1 and 2). 
Table 1 Real-Time PCR Master Mix

\begin{tabular}{ll}
\hline Item & Volume \\
\hline 2x PCR Master Mix (polymerase, dNTPs) & $8 \mu \mathrm{l}$ \\
Sample (cDNA) & $1.6 \mu \mathrm{l}$ \\
Primers (forward/reverse) $1.0 \mu \mathrm{M}$ (Table 2) & $1.6 \mu \mathrm{l} / 1.6 \mu \mathrm{l}$ \\
Distilled water & $3.2 \mu \mathrm{l}$ \\
\hline
\end{tabular}

For every patient, two PCR reaction mixtures were prepared, for the assay of cytokine mRNA and $\beta$-actin mRNA expression levels in RNA isolated from the samples collected from all cases. A $15-\mu \mathrm{L}$ reaction mixture containing $10 \%(\mathrm{v} / \mathrm{v})$ of synthesized cDNA and $1 \mu \mathrm{M}$ of each primer were loaded into each channel of LabChip. LabChip filled with reaction mixture was placed onto the LabChip case and further injected into the ultra-fast LabChip real-time PCR G2-3 system. Real-time PCR was performed according to software protocol (pre denaturation at $95 Æ C$ for $8 \mathrm{~s}$ then 30 cycles at $95 Æ C$ for 8 $\mathrm{s}$ and $72 Æ C$ for $14 \mathrm{~s}$ ). As real-time PCR proceeded, realtime data were plotted on the screen and then sigmoidal curves for amplified DNAs appeared. After curve fitting, $\mathrm{Ct}$ (cycle threshold) values and reaction time of real-time PCR (15 min for 30 cycles) appeared on the screen. Each reaction included the no template control (NTC) to determine whether it was positive or negative. A sample with a Ct value less than 31 was considered positive, in cases where the $\mathrm{Ct}$ value of the NTC was not assigned; $\beta$-actin was treated as the internal control and results were expressed as cytokine/ $\beta$-actin ratio. Target concentration was expressed in relation to the concentration of the housekeeping gene. For relative quantization, the values obtained were compared to those from the standard RNA dilutions which were amplified by the RT-PCR in parallel: relative cytokine expression $=$ copy no of cytokines/copy no of $\beta$-actin = concentration of cytokines $/$ concentration of $\beta$-actin [21].

The research work in this study was done in the Departments of Medical Parasitology and Clinical Pathology in the Faculty of Medicine, Cairo University, and Department of Molecular Biology, Faculty of Medicine, Ain Shams University.

Table 2 Sequence of primers used for quantitative real-time PCR

\begin{tabular}{lll}
\hline Gene & Forward primer (5'-3 ' & Reverse primer (5'-3') \\
\hline$\beta$-actin & GTGGGGCGCCCAGGCACCAG & TCCTAATGTCACGCACGATTC \\
TNF-a & ACCATGAGCACTGAAAGCAT & AGATGAGGTACAGGCCCTCT \\
IFN- $\gamma$ & TTGGGTTCTCTTGGCTGTTA & AAATATTGCAGGCAGGACAA \\
TGF- $\beta$ & CCCAGCATCTGCAAAGCTC & GTCAATGTACAGCTGCCGCA \\
IL-10 & GGTTGCCAAGCCTTGTCTGA & AGGGAGTTCACATGCGCCT \\
\hline
\end{tabular}

\section{Ethical considerations}

Each patient individually signed an informed written consent, before being included in the present study. The current study was carried out in accordance with The Code of Ethics of The World Medical Association of Helsinki for experiments in Humans.

\section{Statistical analysis}

The data collected in this study were evaluated using the PRISM $^{\circ}$ 5.01(GraphPad Software Inc., San Diego, CA, USA.) Data were statistically described in terms of mean \pm standard deviation $( \pm S D)$, median and range, or frequencies (number of cases) and percentages when appropriate. Comparisons between two groups were made using the Student's $t$ test. For the analysis of numerical data when samples failed to show a normal distribution, the Mann-Whitney $U$ test was used for comparison between two groups, while the Kruskal-Wallis test was used for comparing 3 groups together. The Pearson chisquare test was used for categorical data. The relation between variables was examined with correlation analysis using the Spearman rank correlation equation. $p$ values of $<0.05$ were considered as statistically significant.

\section{Results}

The present work comprised a total of 61 women, whose sera were serologically positive either for IgG alone or for both IgG and IgM Toxoplasma antibodies at least by 2 testing techniques. However, none of these seropositively reactive women had apparent constitutional symptoms of toxoplasmosis. The detection of combined seropositivity IgG + IgM against Toxoplasma was significantly higher in group I $(p=0.001)(74 \%(14 / 19))$ compared to group II and group III (21\% (6/28) and 43\% (6/ 14), respectively) as shown in Table 3 and Fig. 1.

Concerning pro- and anti-inflammatory cytokine gene expression, seven representative samples were selected from each of the three study groups, taking into consideration to include the IgM-positive samples; this comprised a total of 21 samples, with 2 samples of them (first in group I, second in group II) being only IgG anti-Toxoplasma serologically positive, but these both samples were positive to Toxoplasma B1 gene by GPCR (unpublished data). The gene expression values of different cytokines in the three groups were analyzed individually in relation to other cytokines tested and in relation to different groups as demonstrated in Table 4. The detected IFN- $\gamma$ expression in groups I, II, and III showed the highest level (mean $=0.294 \pm 0.108)$ in group I. The detected differences in IFN- $\gamma$ expression levels in the three study groups collectively were statistically significant $(p=0.0001)$ as shown in Fig. 2a and Table 4. 
Table 3 Results of serological assays for detection of anti-Toxoplasma antibodies among cases in the study groups

\begin{tabular}{llll}
\hline Serum anti-Toxoplasma antibodies & Group I (abortion) & Group II (no abortion) & Group III (successful outcome and abortion) \\
\hline $\operatorname{lgG}+\operatorname{lgM}(\%)$ & $14(74 \%)$ & $6(21 \%)$ & $6(43 \%)$ \\
$\operatorname{lgG}(\%)$ & $5(26 \%)$ & $22(79 \%)$ & $8(57 \%)$ \\
Total (100\%) & $19(100 \%)$ & $28(100 \%)$ & $14(100 \%)$ \\
Chi-square test $(p$ value) & 0.001 & 0.001 & 0.00594 \\
\hline
\end{tabular}

Concerning TNF- $\alpha$, it was the highest expressed (mean $=0.217 \pm 0.053$ ) in group I when compared to groups II and III (mean $=0.060 \pm 0.020$ and mean $=$ $0.094 \pm 0.018$, respectively). Significant differences were obtained between TNF- $\alpha$ expression levels in group I and group II $(p=0.0006)$ and between group II and group III $(p=0.007)$. The difference detected among the three study groups was remarkably statistically significant $(p=0.0003)$ as shown in Fig. $2 \mathrm{~b}$ and Table 4.

Regarding the anti-inflammatory cytokine gene expression analysis, IL-10 expression tended to be balanced in the three groups. Differences in IL-10 expression between each two groups or between the three groups were statistically non-significant $(p=0.16)$ (Table 4 and Fig. 2c). Similarly, TGF- $\beta$ gene expression was higher in group I (mean $=0.124 \pm 0.35)$, when compared to groups II and III (mean $=0.075 \pm 0.034$ and mean $=0.092 \pm$ 0.031 , respectively) (Table 4 and Fig. $2 \mathrm{~d}$ ). The difference in TGF- $\beta$ gene expression was statistically significant only between group I and group II $(p=0.03)$ (Fig. 2d) but was non-significant among the three study groups $(p=0.089)$ as shown in Table 4 and Fig. 2 d.

IFN- $\gamma$ showed the highest level of expression together with TNF- $\alpha$ level, that both (IFN- $\gamma$ and TNF- $\alpha$ ) were found upregulated than the other two anti-inflammatory cytokines (IL-10 and TGF- $\beta$ ), denoting a predominant inflammatory state in the group I of women, who suffered from repeated abortion without any successful gestational outcome as shown in Fig. 3a. In group1, the differences between both pro-inflammatory IFN- $\gamma$ and TNF- $\alpha$ and both anti-inflammatory IL-10 and TGF- $\beta$ cytokine gene expression levels were significant with detailed $p$ values shown in Fig. 3a.

In Fig. 3b, the four cytokines were approximately in a balanced state in group II, with a little shift towards the 2 anti-inflammatory cytokines (IL-10 and TGF- $\beta$ ). This group of multiparous women with no history of abortions in spite of anti-Toxoplasma seropositivity did not show an observable elevation of any particular cytokine gene expression, as shown in Fig. 3b.

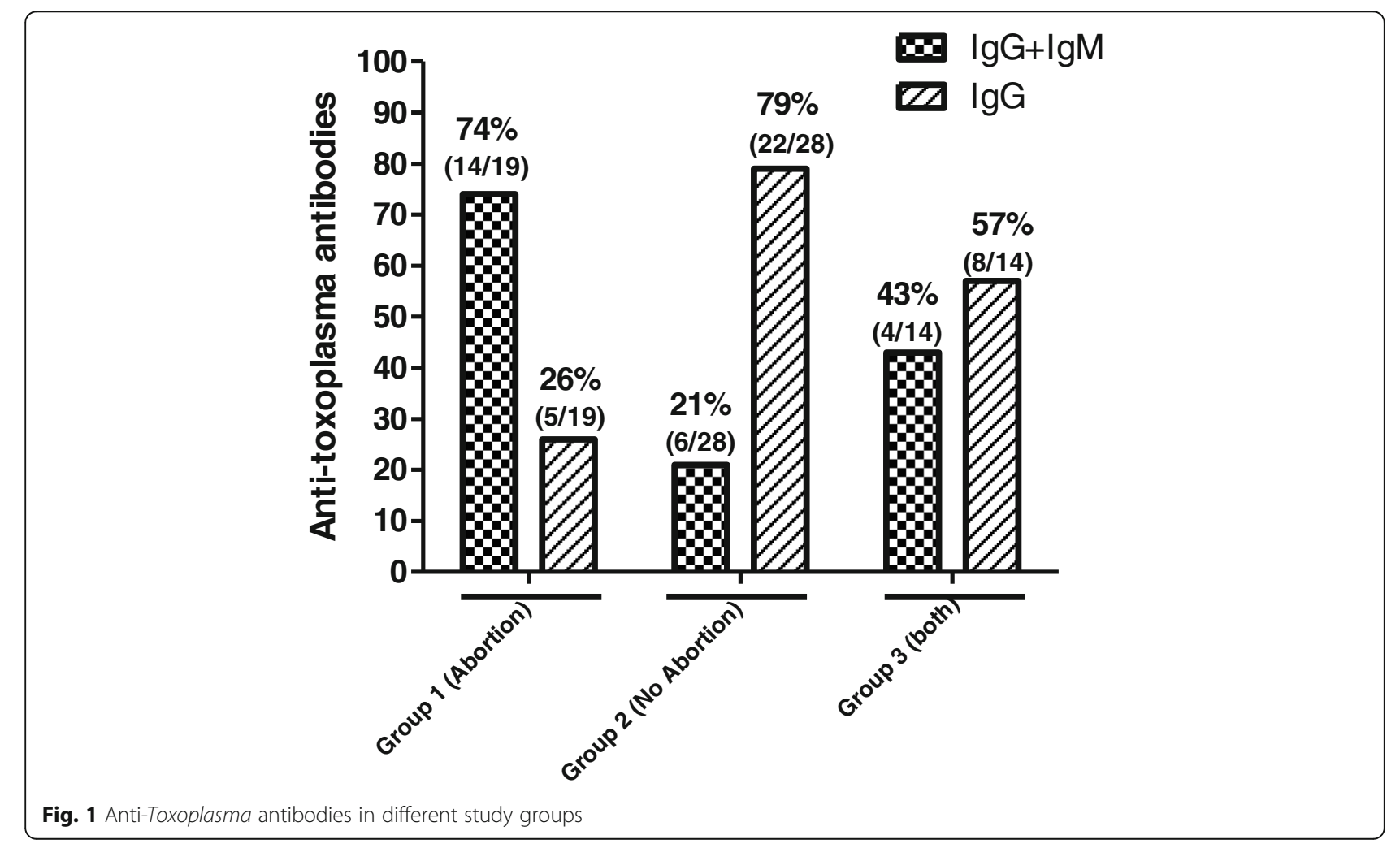


Table 4 Mean values for gene expression for different cytokines in different groups. Calculated $p$ value comparing the 3 study groups using the Kruskal-Wallis test, with a $p$ value $<0.05$ considered significant

\begin{tabular}{lllll}
\hline & Group I (abortion) & Group II (no abortion) & Group III (successful outcome and abortion) & Kruskal-Wallis test ( $p$ value) \\
\hline IFNy (Mean \pm St.Dev.) & $0.294 \pm 0.108$ & $0.051 \pm 0.021$ & $0.102 \pm 0.016$ & 0.0001 \\
TNFa (Mean \pm St.Dev.) & $0.217 \pm 0.053$ & $0.060 \pm 0.020$ & $0.094 \pm 0.018$ & 0.0003 \\
IL10 (Mean \pm St.Dev.) & $0.124 \pm 0.028$ & $0.081 \pm 0.040$ & $0.107 \pm 0.040$ & 0.1632 \\
TGF- $\beta$ (Mean \pm St.Dev.) & $0.124 \pm 0.035$ & $0.075 \pm 0.034$ & $0.092 \pm 0.031$ & 0.0894 \\
\hline
\end{tabular}

In group III, the gene expression level of IL-10 was the highest (mean $0.107 \pm 0.040$ ) compared to other cytokines in the same group, however, with no statistical significance $(p=0.16)$ as shown in Table 4 and Fig. 3c.

The analysis of associations between different cytokines in the three groups was illustrated in Figs. 4 and 5. In groups I and III, there was a positive correlation tendency yet statistically insignificant between both pro-inflammatory cytokines IFN- $\gamma$ and TNF- $\alpha$ (Fig. 3a, e), as well as between both anti-inflammatory cytokines IL-10 and TGF- $\beta$ (Fig. 3b, f). Such correlations were significantly positive in group II ( $p=0.002$ and $p=0.0008$, respectively) as shown in Fig. 3c and d.

Furthermore, a positive insignificant correlation between pro-inflammatory cytokine IFN- $\gamma$ and anti-inflammatory

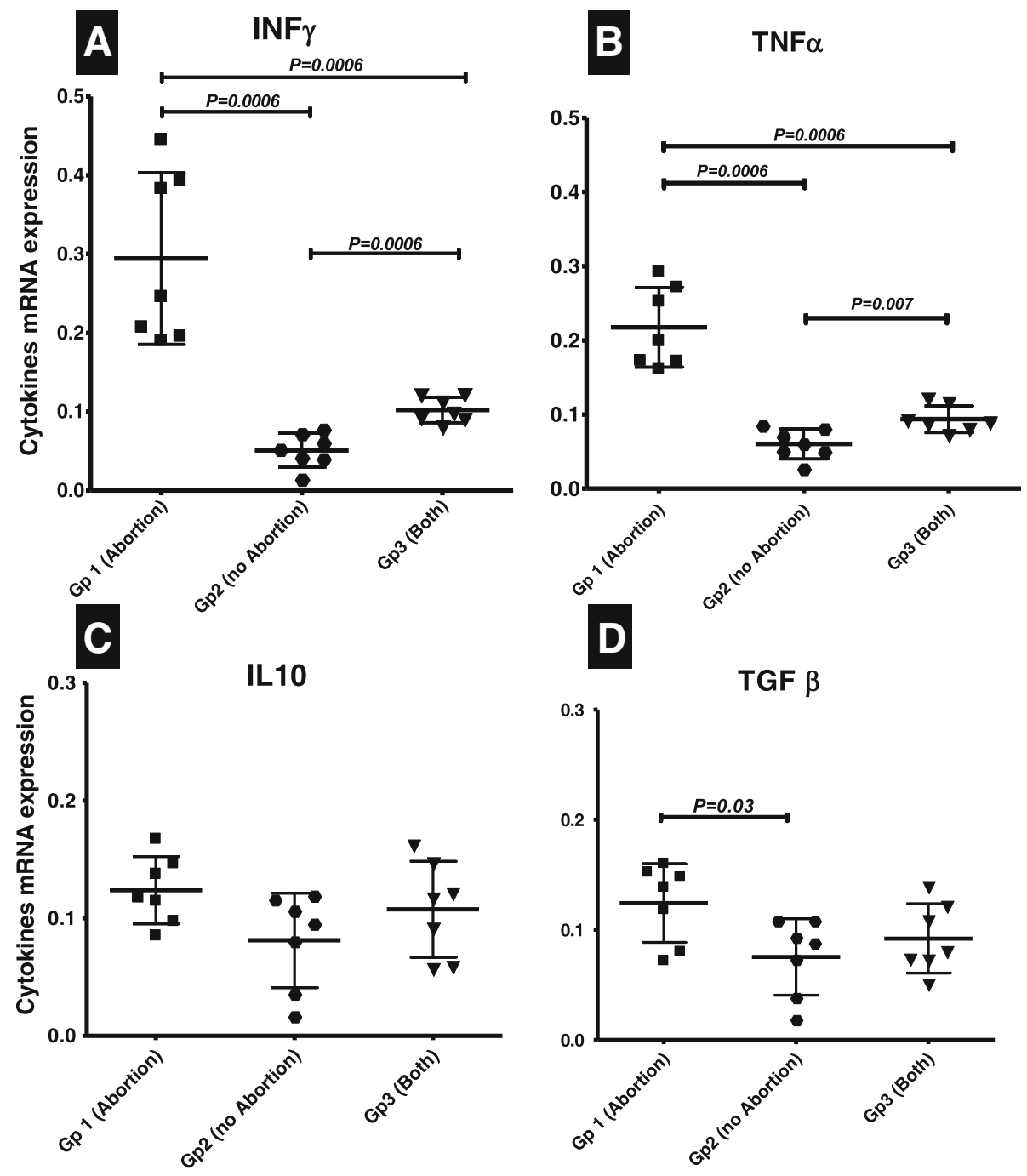

Fig. 2 Gene expression values of different cytokines, a IFN- $\gamma$, b TNF- $a, \mathbf{c} \| \mathrm{L} 10$, and $\mathbf{d}$ TGF- $\beta$ within study groups of Toxoplasma seropositive patients. Calculated $p$ values are shown on the graph; $p$ value $<0.05$ is considered significant 

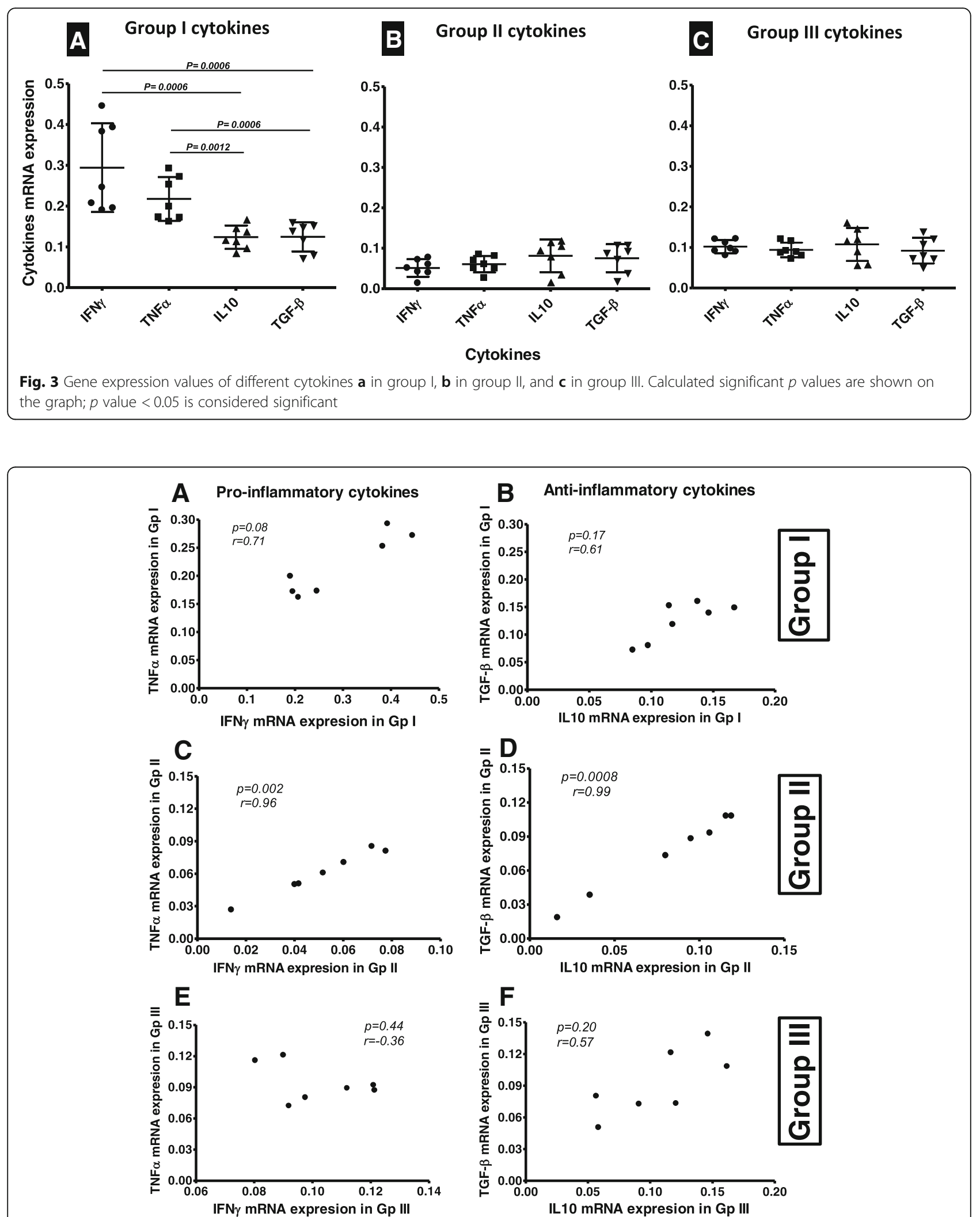

Fig. 4 Positive insignificant correlation between the pro-inflammatory and anti-inflammatory cytokines in group I in $\mathbf{a}$ and $\mathbf{b}$ and in group III in $\mathbf{e}$ and $\mathbf{f}$. Positive significant correlation between the pro-inflammatory and anti-inflammatory cytokines in group II in $\mathbf{c}$ and $\mathbf{d}$, with correlation coefficient $r$ and calculated $p$ values shown on the graph; $p$ value $<0.05$ is considered significant 


\section{Correlation between IFN $\gamma$ and IL10}
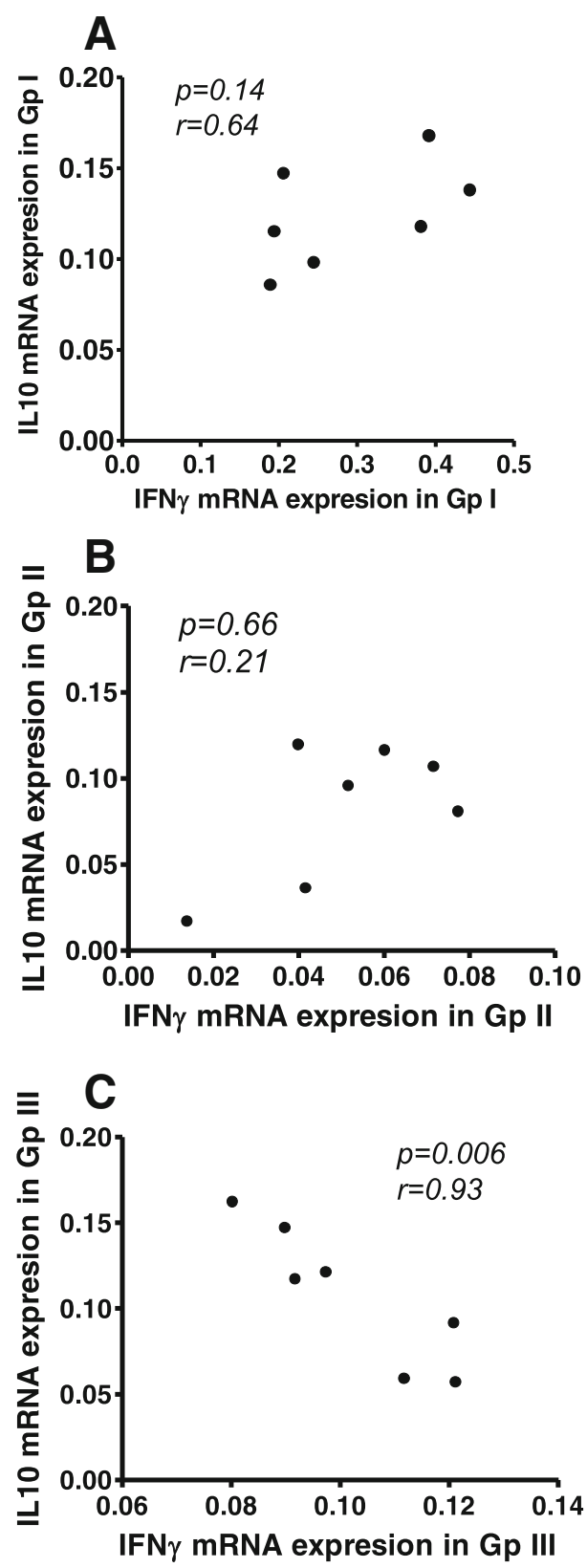

Fig. 5 Correlation between IFN $\gamma$ and anti-inflammatory cytokines IL10 in all groups, positive insignificant correlation between IFN- $\gamma$ and anti-inflammatory cytokine (IL-10) in group I (a) and group II (b) and significant negative correlation detected between IFN $\gamma$ and IL10 in group III (c), with correlation coefficient $r$ and calculated $p$ values shown on the graph; $p$ value $<0.05$ is considered significant

cytokine IL-10 in groups I and II was detected as shown in Fig. 5a-d. However, in group III, a strongly significant negative correlation was detected ( $p=0.006, r=-0.93$ ) between IFN $\gamma$ and IL10 as shown in Fig. 5c. On the other hand, no association between IFN- $\gamma$ and TGF- $\beta$ was detected in all groups.

\section{Discussion}

Since the pathogenicity of the abortive consequence of pregnancy is explained through the net result of immunological state, which is mediated through cytokine release, our study was concerned with cytokine expression profile in Toxoplasma-seropositive cases with variant pregnancy outcomes.

Anti- Toxoplasma IgM appears 14 days after infection and disappears several months later, with the possibility of its early disappearance, or persistence over time, even for as long 3-4 years [22]. However, still, it is considered that the presence of a Toxoplasma-specific IgM antibody combined with high IgG titer indicates acute or reactivation of infection within the previous 3 months [23, 24].

Th1 cells are involved in cell-mediated inflammation and produce pro-inflammatory cytokines, which inhibit trophoblast growth and differentiation and produce cytokines as IFN- $\gamma$ resulting in recurrent abortion [25, 26]. Additionally, Th1-type cytokines induce apoptosis that could jeopardize the trophoblast barriers separating the semi-allogenic fetus from the mother's immune system, leading to fetal rejection or abortion. These cytokines initiate the development of natural killer cells, lymphokineactivated killer cells, and CTL cells that cause fetal death, as they are capable of killing trophoblasts [27].

The immunological paradox of pregnancy is still not fully comprehended. It was proposed that a healthy pregnancy is accompanied by a decreased Th1/Th2 balance; nevertheless, other studies argued against this concept [28]. Pregnancy as a physiological condition is characterized by fluctuation between being pro-inflammatory and anti-inflammatory response depending upon the stage of gestation [29, 30]. Any dysfunction of this well-tailored immunological status leads to the production of pro-inflammatory cytokines such as IFN- $\gamma$ and TNF- $\alpha$ and may be extremely harmful to pregnancy [31-33].

Increased production of some inflammatory cytokines during pregnancy could play an essential role in the development of severe forms of the Toxoplasma infection including abortion, which may be attributed to different Toxoplasma strains [34]. The ability of different forms of $T$. gondii to induce a Th1 response may be sufficient to induce abortion during the first trimester, when pregnancy-induced Th2 bias is low. In contrast, in the third trimester; pregnancy has induced a strong Th2 polarization that may counteract the $T$. gondii-induced Th1 response and prevent stillbirth or preterm labor. As a consequence, parasite survival may be favored in the third trimester and account for the increased rates of transmission [35].

In our study, cases in group I reported a high level of IgM and IFN- $\gamma$, in agreement with Abo Bacar et al. [36] who stated that IFN- $\gamma$ is increased during acute Toxoplasma infection. Blader and Saeij [6] reported that IFN- $\gamma$ 
is produced in response to parasite stimulation of IL-12 expression, which is the critical cytokine for resistance to both acute and chronic Toxoplasma infections.

Our study revealed that women of group I showed a statistically significant increase in the expression of TNF- $\alpha$, compared to groups II and III. The role of TNF$\alpha$ in causing abortion could be due to its action as a pro-inflammatory cytokine that causes uterine contraction and necrosis of implanted embryo by thrombosing its blood supply leading to fetal expulsion [37, 38]. IFN$\gamma$ and TNF- $\alpha$ cause pregnancy failure by two independent but superimposed mechanisms: systemic inhibition of ovarian function and local induction of inflammatory process within implantation sites [39, 40].

Inversely; cases in group II did not suffer any abortions, in spite of being Toxoplasma seropositive; this could be explained by a well-adjusted status between two opposing immunological fronts, which was demonstrated in the current study, through convincing association between pro-inflammatory cytokines IFN- $\gamma$ and TNF- $\alpha$ combined expression. On the other frontage, both anti-inflammatory IL-10 and TGF- $\beta$ cytokine expression were strongly associated. This balanced and harmonized state seemed to be essential to achieve successful pregnancy outcome in group II, rather than higher levels of these cytokine expressions. Initiation of the Th2 pathway and production of anti-inflammatory cytokines promote embryonic and placental development and deficiency of these anti-inflammatory cytokines leads to poor placental development, subnormal growth, and even fetal death. Moreover; these anti-inflammatory cytokines antagonize the harmful action of Th1-dependent cytokines [16, 37, 41]. Cases included in group II showed no abortions; however, they did not record the highest expression levels of anti-inflammatory cytokines among our study groups.

In agreement with our conclusion, other studies reported that the balance between IFN- $\gamma$ and other pro-and anti-inflammatory cytokines and the stage of gestation at which IFN- $\gamma$ is produced are fundamental in determining whether IFN- $\gamma$ plays a physiological or pathological role $[42,43]$.

In accordance with our results, Taher and Abdullah [40] reported an increase of IL-10 mean percentage in the placenta of aborted women infected with $T$. gondii compared to that produced by the placenta of aborted women uninfected with $T$. gondii and induced aborted women. The relatively high level of the anti-inflammatory cytokine (IL10) accompanied by significant downregulation of pro-inflammatory cytokine (IFN- $\gamma$ ) expression, shown in group III, indicated the possible regulatory role of cytokine (IL10) in saving some pregnancies' outcomes in this group. In this context, Gaddi and Yap [44] reported that modification of the immune response by TGF- $\beta$ and IL-10 is crucial to the outcome of Toxoplasma gondii infection; however; it looked like that the significantly high level of TGF- $\beta$ expression in group I compared to group II was not sufficient to modulate or to control the significantly higher levels of the synergistic action of both IFN- $\gamma$ and TNF- $\alpha$.

Concerning the impact of IFN- $\gamma$ on anti-inflammatory cytokines, there was no statistically significant correlation between IFN- $\gamma$ and both anti-inflammatory cytokines IL-10 and TGF- $\beta$ in groups I and II, which may imply a weak influence of IFN- $\gamma$ on anti-inflammatory cytokines in these groups with two extreme limits of clinical forms of toxoplasmosis.

Our findings valued gene expression profiling in Toxoplasma gondii infections, in relation to the severity of clinical picture. This was in accord with Alizadeh et al. [45], who demonstrated that gene expression profiling was able to predict poor prognosis that was not predicted by clinical criteria alone. Identification of these high-risk patients by gene expression profiling may, in the future, influence treatment decisions as well as patient selection in clinical trials of new therapeutics [46].

\section{Conclusion}

This study demonstrated variable cytokine expression profiles regarding different pregnancy outcome in Toxoplasma seropositive women and emphasized that cytokine gene expression is a valuable parameter for estimating patho-immunological effect of Toxoplasma infection (latent or active), whether towards upregulating the pro-inflammatory cytokine axis resulting in an imbalanced immunological state in the first trimester resulting in lethal gestational consequences or maintaining a harmonized immunological balance, in spite of still harboring the infection as in multiparous women. This verifies the complex relation between pro-inflammatory and anti-inflammatory cytokines in relation to diverse pregnancy outcomes in Toxoplasma infection.

\section{Abbreviations}

DC: Dendritic cells; ELISA: Enzyme-linked immunosorbent assay; IFNY: Interferon gamma; IgG: Immunoglobulin G; IL10: Interleukin 10; mRNAs: Messenger ribonucleic acid; OD: Optical density; qPCR: Quantitative polymerase chain reaction; RNA: Ribonucleic acid; RT-qPCR: Reverse transcription-quantitative polymerase chain reaction; SAGE: Serial analysis of gene expression; TGF- $\beta$ : Transforming growth factor beta; Th2: T-helper 2; Thl: T-helper 1; TNF-a: Tumor necrosis factor alpha

\section{Acknowledgements}

Not applicable

\section{Author contributions}

ME participated in the design of the study, carried out the serological and molecular assays, and drafted the manuscript. AAA participated in the design of the study, carried out the serological and molecular assays, and drafted the manuscript. WSE participated in the design of the study, carried out the clinical examination of cases, and helped to draft the manuscript. SSA participated in the design of the study, helped in serological and molecular assays, and drafted the manuscript. IZA participated in the design of the 
study and performed the statistical analysis. GMN participated in the design of the study and helped in statistical analysis. MS participated in the design of the study and helped in statistical analysis. MSB participated in the design of the study and carried out the serological and molecular assays. All authors read and approved the final manuscript.

\section{Funding}

This research received no specific grant from any funding agency.

\section{Availability of data and materials}

All data generated or analyzed during this study are included in this published article.

\section{Ethics approval and consent to participate}

All procedures performed in studies involving human participants were in accordance with the ethical standards of the institutional and/or national research committee and with the 1964 Helsinki declaration and its later amendments or comparable ethical standards. This research was approved by the Research Ethics Committee of the Faculty of Medicine, Cairo University (N-51-2013). Written informed consents were obtained from participants in this study. All authors accepted the publication. The data used or analyzed during the study are available from the corresponding author on reasonable request.

\section{Consent for publication}

Not applicable

\section{Competing interests}

The authors declare that they have no competing interests.

\section{Author details}

'Department of Medical Parasitology, Faculty of Medicine, Cairo University, Giza, Egypt. ${ }^{2}$ Department of Medical Parasitology, Armed Forces College of Medicine (AFCM), Heliopolis, Egypt. ${ }^{3}$ Department of Obstetrics \& Gynaecology, Faculty of Medicine, Cairo University, Giza, Egypt. ${ }^{4}$ Department of Molecular Diagnostics, Genetic Engineering and Biotechnology Research Institute, University of Sadat City, Sadat City, Egypt. ${ }^{5}$ Faculty of Science, Ain Shams University, Cairo, Egypt. ${ }^{6}$ Department of Molecular Biology, Medical Research Center, Faculty of Medicine, Ain Shams University, Cairo, Egypt.

\section{Received: 26 June 2019 Accepted: 21 July 2019}

\section{Published online: 15 August 2019}

\section{References}

1. Yang W, Alan Lindquist H, Cama V, Schaefer F, Villegas E, Fayer R, Lewis E (2009) Detection of Toxoplasma gondii oocysts in water sample concentrates by Real-Time PCR. Appl Environ Microb 75(11):3477-3483

2. Sarkar M, Anuradha B, Sharma N, Roy R (2012) Seropositivity of Toxoplasmosis in antenatal women with bad obstetric history in a tertiary-care Hospital of Andhra Pradesh, India. J Health Popul Nutr 30(1):87-92

3. Al-Hamdani M, Mahdi N (1996) Toxoplasmosis among women with habitual abortion. EMHJ 3(2):310-315

4. Ebadi P, Solhjoo K, Bagheri K, Eftekhar F (2011) Seroprevalence of toxoplasmosis among the women with recurrent spontaneous abortion in comparison with the women with uncomplicated delivery. J Jahrom Univ Med Sci 9:1

5. Brown K, Blader I (2009) The role of DNA microarrays in Toxoplasma gondii research, the causative agent of ocular toxoplasmosis. J Ocul Biol Dis Infor 2(4):214-222

6. Blader I, Saeij J (2009) Communication between Toxoplasma gondii and its host: impact on parasite growth, development, immune evasion, and virulence. APMIS 117(5-6):458-476

7. Sher A, Denkers E, Gazzinelli R (1995) Induction and regulation of host cellmediated immunity by Toxoplasma gondii. CIBA Found Symp 195:95-104

8. Del Rio L, Bennouna S, Salinas J, Denkers E (2001) CXCR2 deficiency confers impaired neutrophil recruitment and increased susceptibility during Toxoplasma gondii infection. J Immunol 167:6503-6509

9. Khan A, Murphy P, Casciotti L, Schwartzman J, Collins J, Gao J, Yeaman G (2001) Mice lacking the chemokine receptor CCRI show increased susceptibility to Toxoplasma gondii infection. J Immunol 166:1930-1937

10. Bennouna S, Bliss S, Curiel T, Denkers E (2003) Cross-talk in the innate immune system: neutrophils instruct recruitment and activation of dendritic cells during microbial infection. J Immunol 171:6052-6058
11. Aliberti J, Valenzuela J, Carruthers V, Hieny S, Andersen J, Charest H, Reis e Sousa C (2003) Molecular mimicry of a CCR5 binding-domain in the microbial activation of dendritic cells. Nat Immunol 4:485-490

12. Ocana-Morgner C, Mota M, Rodriguez A (2003) Malaria blood stage suppression of liver stage immunity by dendritic cells. J Exp Med 197:143-151

13. Yap G, Pesin M, Sher A (2000) Cutting edge: IL-12 is required for the maintenance of IFN- $\gamma$ production in T cells mediating chronic resistance to the intracellular pathogen, Toxoplasma gondii. J Immunol 165:628-631

14. Entrican $\mathrm{G}$ (2002) Immune regulation during pregnancy and host-pathogen interactions in infectious abortion. J Comp Pathol 126:79-94

15. Wegmann T (1984) Foetal protection against abortion: is it immunosupression or immunostimulation? Ann Immunol 135D:309-312

16. Wegmann T, Lin H, Guilbert L, Mosmann T (1993) Bidirectional cytokine interactions in the maternal-fetal relationship: is successful pregnancy a Th2 phenomenon? Immunol Today 14(7):353-356

17. Mor G (2007) Pregnancy reconceived. Natural History 116:36-41

18. Mor G, Koga K (2008) Macrophages and pregnancy. Reprod Sci 15:435-436

19. Barbosa B, Silva D, Costa I, Mineo J, Ferro E (2008) BeWo trophoblast cell susceptibility to Toxoplasma gondii is increased by interferon-gamma, interleukin10 and transforming growth factor-beta1. Clin Exp Immunol 151(3):536-545

20. Das H, Koizumi T, Sugimoto T, Chakraborty S, Ichimura T, Hasegawa K Nishimura R (2000) Quantitation of Fas and Fas ligand gene expression in human ovarian, cervical and endometrial carcinoma using real-time quantitative RT-PCR. Br J Cancer 82:1682-1688

21. Suzuki T, Higgins P, Crawford D (2000) Control selection for RNA quantitation. Biotechniques 29:332-337

22. Montoya J (2002) Laboratory diagnosis of Toxoplasma gondii infection and toxoplasmosis. J Infect Dis 15(185 Suppl 1):S73-S82

23. Jin S, Chang ZY, Ming X (2005) Fast dipstick dye immunoassay for detection of immunoglobulin $\mathrm{G}(\mathrm{lgG})$ and $\operatorname{lgM}$ antibodies of human toxoplasmosis. Clin Diagn Lab Immunol 12:198-201

24. De Paschale M, Agrappi C, Belvisi L (2008) Revision of the positive predictive value of IgM anti-Toxoplasma antibodies as an index of recent infection. New Microbiol 31:105-111

25. Hill J, Anderson D, Polgar K (1995) T helper 1-type cellular immunity to trophoblast in women with recurrent spontaneous abortions. JAMA 273:1933-1936

26. Shiono Y, Hye-Seong M, Na H, Yuka N, Fang Hao FM (2007) Maternalfoetal transmission of Toxoplasma gondii in IFN- $\gamma$ deficient pregnant mice. Parasitol Int 56:141e8

27. Drake B, Head J (1989) Murine trophoblasts can be killed by lymphokine activated killer cells. J Immunol 143:9-17

28. Mor D, Cardenas S (2011) The immune system in pregnancy: a unique complexity. Am J Reprod Immunol 63(6):425-433

29. Romero R (2005) Novel aspects of neutrophil biology in human pregnancy. Am J Reprod Immunol 53:275

30. Mor G (2008) Inflammation and pregnancy: the role of toll-like receptors in trophoblast-immune interaction. Ann N Y Acad Sci 1127:121-128

31. Ashkar A, Di Santo J, Croy B (2000) Interferon gamma contributes to initiation of uterine vascular modification, decidual integrity, and uterine natural killer cell maturation during normal murine pregnancy. J Exp Med 192:259-270

32. Greenwood J, Minhas K, di Santo J, Makita M, Kiso Y, Croy B (2000) Ultrastructural studies of implantation sites from mice deficient in uterine natural killer cells. Placenta 21:693-702

33. Le Bouteiller P, Piccinni M (2008) Human NK cells in pregnant uterus: why there? Am J Reprod Immunol 59:401-406

34. Araujo F, Slifer T (2003) Different strains of Toxoplasma gondii Induce Different Cytokine Responses in CBA/Ca Mice. Infection and Immunity 71(7):4171-4174

35. Saito S (2000) Cytokine network at the foeto-maternal interface. J Reprod Immunol 47:87-103

36. Abou-Bacar A, Pfaff A, Georges S, Letscher-Bru V, Filisettiy D (2004) Role of NK cells and gamma interferon in transplacental passage of Toxoplasma gondii in a mouse model of primary infection. Infect Immun 72:1397-1401

37. Raghupathy R (1997) Th-1 type immunity is incompatible with successful pregnancy. Immunol Today 10:478-482

38. Daher S, de Arruda GeraldesDenardi K, Blotta M, Mamoni R, Reck A, Camano L, Mattar $R$ (2004) Cytokines in recurrent pregnancy loss. J. Reprod Immunol 62:151-157

39. Erlebacher A, Zhang D, Parlow A, Glimcher L (2004) Ovarian insufficiency and early pregnancy loss induced by activation of the innate immune system. J Clin Invest 114:39-48

40. Taher j AA (2012) Possible role of some aspects of immune response in aborted women infected with Toxoplasma gondii. Al Kufa J Biol 4:1): 1-1): 8 
41. Romagnani S (1994) Lymphokine production by human T cells in disease states. Ann Rev Immunol 12:227-237

42. Panes A, Perry M, Granger D (1999) Leukocyte-endothelial cell adhesion: avenues for therapeutic intervention. Brit J Pharma 126:537-550

43. Gagioti S, Scavone C, Bevilacqua E (2000) Participation of the mouse implanting trophoblast in nitric oxide production during pregnancy. Biol Reprod 62:260-268

44. Gaddi P, Yap G (2007) Cytokine regulation of immunopathology in toxoplasmosis. Immunology and Cell Biology 85:155-159

45. Alizadeh A, Eisen M, Davis R, Ma C, Lossos I, Rosenwald A (2000) Distinct types of diffuse large B-cell lymphoma identified by gene expression profiling. Nature 403:503-511

46. Golub T, Slonim D, Tamayo P, Huard C, Gaasenbeek M, Mesirov J (1999) Molecular classification of cancer: class discovery and class prediction by gene expression monitoring. Science 286:531-537

\section{Publisher's Note}

Springer Nature remains neutral with regard to jurisdictional claims in published maps and institutional affiliations.

\section{Submit your manuscript to a SpringerOpen ${ }^{\circ}$ journal and benefit from:}

- Convenient online submission

- Rigorous peer review

- Open access: articles freely available online

High visibility within the field

- Retaining the copyright to your article

Submit your next manuscript at $\boldsymbol{\nabla}$ springeropen.com 